\title{
COMPRENSIÓN POÉTICA Y TRADUCCIÓN: LA OBRA LÍRICA DE SAMUEL BECKETT
}

\author{
David Lagmanovich \\ Universidad Nacional de Tucumán
}

El objetivo de estas páginas es doble. Por una parte, quisiera presentar aspectos de la obra poética de Samuel Beckett en inglés y en francés; y el hablar de los poemas de Beckett es referirse a aquellos textos que con seguridad constituyen la parte menos conocida de su producción. Por la otra, me interesa mostrar, a través de ejemplos concretos, algunos de los problemas que aparecen en el proceso de la traducción poética. En un caso como en el otro, giramos alrededor del fenómeno central de la poesía, ese misterio que, no obstante, los lectores habituales de literatura tratamos empeñosamente de desentrañar.

\section{Beckett y nuestra poesía}

Permitaseme comenzar estas notas con una mención -queimprevistamente para muchos relaciona a Samuel Beckett con nuestra poesía, la poesía en lengua española.

En 1958, en la colección de obras representativas publicada por iniciativa de la UNESCO, apareció, a través de la Indiana University Press, la versión inglesa de la antologia de la poesía mexicana compilada por Octavio Paz ${ }^{1}$. La antología arranca en el siglo XVI, 'con la figura borrosa de Francisco de Terrazas, y prudentemente concluye hacia 1910, con la figura consular de Alfonso Reyes. No hay allí poetas más cercanos a nosotros en el tiempo: tal vez porque, si se hubiera pretendido incluirlos, se habría tornado necesario dilucidar el lugar que ocupaba entonces, en la poesía de su país, el propio Octavio Paz. Lo que aqui nos interesa: el traductor de esa antología en su versión inglesa (pues también se la tradujo al francés) es Samuel Beckett.

Es decir: uno de los más revolucionarios escritores de siglo $X X$ traduce un conjunto de bellos poemas tradicionales, que corresponden mayoritariamente a los cuatro siglos anteriores. El hecho en sí mismo podria considerarse una curiosidad literaria. Pero hay más. Revisando las traducciones, uno encuentra detalles que se pueden reinterpretar a la luz de lo que sabemos de Beckett. Por ejemplo, la soltura con que traduce los haiku de José Juan Tablada, cuya concepción de una poesia fragmentaria debe de haberle encantado: "Tender willow / almost gold, almost amber, I almost light..." (150) para aquel famoso dedicado al sauce, o saúz: "Tiemo saúz, / casi oro, casi ámbar, / casi luz..." Fragmentarismo y repetición: dos rasgos que seguiremos encontrando en sus poemas.

\footnotetext{
' Octavio Paz. comp. An Anthology of Mexican Poetry. Bloomington: Indiana University Press. 1958. Trans. Samuel Beckett. Preface by C. M. Bowra

- Cito por: Federico de Onís. Antología de la poesía española e hispanoamericana (18821932), reimpresión (New York Las Américas Publishing Company. 1961), p.465
} 
Y, de pronto, también otra cosa: la predilección por determinadas palabras (porque todas las palabras son insuficientes, pero a la vez todas son necesarias para nombrar el silencio). Traigo otro ejemplo. Paz incluye, como no podria ser de otra manera, varios poemas de Ramón López Velarde, entre ellos uno muy conocido, "Mi prima Águeda". En ese sugestivo recuerdo infantil, el poeta mexicano evoca: "y mi prima llegaba / con un contradictorio / prestigio de almidón y de temible luto ceremonioso"; también" sus ojos / verdes y sus mejillas rubicundas / me protegían contra el pavoroso / luto... , y finalmente se la define de nuevo, parentéticamente, en función de los rasgos que quedan en la memoria: "(luto, pupilas verdes y mejillas / rubicundas)". ${ }^{3 *}$ Pues bien, las tres veces Beckett traduce "luto" por la palabra que él prefiere, la ambigua "weeds" (y no "mourning", por ejemplo), la misma que usa en su poema "Malacoda" en relación con la presencia del hombre de los servicios fúnebres en la casa familiar después de la muerte del padre: "find the weeds engage them in the garden", "find the weeds engage their attention", dice en aquel poema. ${ }^{5} \mathrm{Y}$ volviendo a lo nuestro, traduciendo a López Velarde: "a conflicting / prestige of starch and fearful / ceremonious weeds"; "her green eyes / and ruddy cheeks protected / me against the fearsome / weeds", y luego el paréntesis sumatorio, "(weeds, green pupils, ruddy cheeks)" (172-73). A lo largo de las traducciones del volumen podemos encontrar otros ejemplos semejantes.

No es este el momento de analizar en detalle las traducciones que existen de poesia de Samuel Beckett al español (aunque bien valdria la pena hacerlo como un proyecto distinto). Lo que quiero señalar es que, aun en una breve explòración, se advierte la capacidad del intelectual para absorber una poesía ajena y trasvasarla a su propia lengua. Pero no sólo a su propia lengua, sino aún al propio idiolecto que ha ido forjando a lo largo de su carrera de escritor: así, la versión alcanza una irrefutable autenticidad.

\section{Las traducciones del francés}

Eso mismo hace Beckett, en forma eminente, en su labor de traductor relacionada con el francés. Por un lado, la versión al inglés de poemas de Eluard, de Rimbaud o de Apollinaire, por citar algunos; por la otra, su ir y venir bien conocido entre el inglés y el francés en su propia poesía (aunque no de toda su poesia haya una doble versión). Leemos, por ejemplo:

${ }^{3}$ Cito por: Eugenio Florit: y Josdé Olivio Jiménez, La poesía hispanoamericana desde el Modernismo (New York: Appleton-Century Crofts, 1968), pp. 190-91.

${ }^{4}$ Samuel Beckett, Collected Poems 1938-1978 (London: John Calder, 1986), p.26

${ }^{5}$ Laura Cerrato, en su versión de "Malacoda"(Beckettiana [Buenos Aires] 4 [1995]: 41-42, traduce correctamente "weeds"por "crespones". Por su parte, Jenaro Talens (Samuel Beckett, Poemas. Barcelona: Barral, 1970, pp. 77-78) prefiere la expresión "un traje de luto": a nuestro entender se aproxima al significado del original, pero es quizá demasiado especifico frente a la generalidad de la palabra inglesa. 
She is standing on my lids

And her hair is in my hair,

She has the colour of my eye.

She has the body of my hand

In my shade she is engulfed

As a stone against the sky.

y nos parece estar escuchando esto otro, que es lo que escribió Paul Éluard;

Elle est debout sur mes paupières

Et ses cheveux sont dans les miens

Elle a la forme de mes mains,

Elle a la couleur de mes yeux,

Elle s'engloutit dans mon ombre

Comme une pierre sur le ciel.

El gran traductor de poesía es un ilusionista: nos da una versión que es también un original, y un original que parece existir al solo efecto de ser traducido a otra lengua. Mil veces se ha dicho que para traducir poesía hay que ser poeta. La experiencia de leer, por ejemplo, a Sor Juana Inés' de la Cruz a través, de Samuel Beckett; afirma la sospecha de que los miembros de esa secta secreta, la de los poetas, se entienden entre si a través de las lenguas y los espacios, a través de los tiempos y las convenciones literarias, para llegar a un solo y único lector.

\section{La obra lírica}

¿Cómo es, pues, la obra lírica de este dramaturgo y novelista, Samuel Beckett?

En primer lugar podemos considerar su extensión dentro de la obra total. Sin duda ese lugar es pequeño, aunque la producción haya sido bastante constante, o sostenida, a lo largo de los años. En la colección publicada por la editorial John Calder (citada en la nota 4), se distinguen tres secciones: poemas en inglés poemas .en francés (algunos de ellos, con traducciones al inglés por el propio autor) y traducciones. Entre los primeros encontramos algunos poemas sueltos -de los cuales sólo uno "Whoroscope" es relativamente extenso-y dos series de poemas breves: "Echo's Bones " ("Los huesos de Eco") y "Seven Poems"; en total, 23 poemas escritos originariamente en inglés. Los poemas en francés son relativamente más numerosos, aunque también ocurre que cada uno de ellos es mucho más breve, y forman a su vez varias series: los "Poemes" de 1937-39, los "Six Poemes" de 1947-49, dos poemas más de 1974, y la serie "Mirlitonnades", de 1976-78. En su totalidad .-y aunque siempre exista la posibilidad de algunas adiciones de inéditos o de poemas aparecidos en revistas aún no revisadas-, la poesía original de Beckett cabe en poco menos de 100 páginas. 
En la edición que consultamos siguen traducciones del francés: de Éluard, Rimbaud (una importante versión de "le Bateau ivre") Apollinaire ("Zone") y un grupo de máximas poemáticas de Sebastien Chamfort. No se reimprime aquí ninguna de las traducciones beckettianas del español.

\section{Un campo de tensiones}

Si vamos ahora -por fin- a los poemas mismos, encontramos ante todo que estos textos trabajan sobre la tensión creada por la referencia simultánea a dos lenguas, que son el inglés y el francés (con perceptibles inserciones, asimismo, del alemán, y en menor medida de otras lenguas). Ahora ya no estoy hablando de la actividad de traducir, sino de un bilingüismo -o más bien plurilingüismo- esencial que se refiere al proceso mismo de la creación.

Esa internacionalización del lenguaje, del cual James Joyce es el ejemplo eminente, tiene que ver también, como se dice en el mundo angloamericano, con el modernismo; es decir, con los fenómenos que nosotros agrupamos bajo el nombre general de vanguardia. Si se acepta la distinción acuñada por Frank Kermode $^{6}$ entre un "paleomodernismo" y un "neomodernismo", Beckett estaría indudablemente comprendido en este segundo grupo. (No ignoro la lúcida discusión de Laura Cerrato" sobre las relaciones entre nuestro escritor y la actitud posmoderna; señalo, simplemente, un origen histórico.) La poesía de Beckett es una poesia de la vanguardia europea y norteamericana, en el sentido en que lo son también las trayectorias poéticas de Eliot y Pound, de Williams y Cummings, de Éluard y Reverdy, y de Ungaretti, Quasimodo y Montale.

Por su origen "modernista" en el sentido apuntado (o "vanguardista", como decimos nosotros), la poesía de Beckett -al igual que el resto de su obra-transparenta ciertas actitudes más 0 menos generalizadas en la literatura del siglo XX que podemos sintetizar asi:

1. Muestra una intención decidida de apartarse de las reglas, tradiciones y convenciones establecidas; es decir quiere ser un "arte en libertad".

2. Manifiesta nuevas maneras de considerar la posición y función del hombre en el universo, a la vez que medita sobre el sentido o sinsentido de éste.

3. En particular, entre las instituciones de la cultura cuestionadas coloca el lenguaje. Con respecto al mismo, objeta su presunto rol mimético, la validez "estética" de sus logros, y la codificación emergente del peso de una tradición que queda sintetizada o cristalizada en el canon literario.

\footnotetext{
${ }^{6}$ Frank Kermode. Modern Essays (1971). Tomo la referencia de Roger Fowler, ed., A Dictionarv of Modern Critical Terms, rev. ed. (London: Routledge and Kegan Paul, 1987), "Modernism"

7 "Postmodernism and Beckett's Aesthetics of Failure"Today/Aujourd'hui 2(número sobre "Beckett in the 1990s"), pp. 21-29.
} 


\section{Hermetismo}

Repasemos ahora la forma en que se realizan algunos de esos rasgos generales en el plano estrictamente poético. Hay, en efecto, una peculiar enunciación -en la lengua hablada la llamariamos una "entonación", quizá hasta una "tonada"- que podemos percibir en los textos poéticos de Beckett, tanto en inglés como en francés.

Advirtamos primeramente que, desde el ángulo del receptor, uno de los resultados inmediatos del contacto con esta poesía es su dificultad verbal, que puede llegar a un punto muy cercano a la ininteligibilidad. La forma rápida -aunque no necesariamente más exacta- de referirse a esta característica es denominarla poesía hermética.

Al lector le faltan puntos de apoyo. Reconoce palabras, pero no un contexto (precisamente, leer en forma inteligente esta poesía, o sea interpretarla, implica restituir un contexto dentro del cual aparezca y circule el significado). La disposición tipográfica le lleva a creer en una intención "artística", por su eventual semejanza con respecto a otros textos de la tradición literaria de su lengua (uso del "verso" y ciertos efectos fónicos correlativos), pero dentro de esa forma las palabras le llegan como membra disyecta, no como parte de un discurso orgánico ("the churn of stale words in the heart again", otra vez el revolverse de palabras rancias en el corazón, caracteriza el propio Beckett en uno de sus poemas ${ }^{8}$ Hay referencias a hechos y nombres de la cultura -a veces en forma directa, otras como alusiones- que no se explicitan: al no ser identificados automáticamente en la lectura, quedan como mojones aislados de un territorio desconocido. La deixis actúa en una forma aun más peculiar que en el discurso poético tradicional, al opacar o vaciar el lugar del referente.

Quizá valga la pena intentar una relación contextual más: la que relacionaría la poesía de Beckett, en primer lugar, con la tendencia de la poesia inglesa llamada minimalismo; tendencia que da por resultado poemas en los cuales la funcionalidad de los elementos que permanecen en la página (después de un proceso de eliminación) es subrayado por su aislamiento icónico. La actitud minimalista no implica solamente reducción textual, sino también la decisión de llegar a un nivel de "afirmación mínima": mínima distinción entre verso y prosa, mínima distancia entre el lenguaje poético y el lenguaje informativo, mínima carga semántica (salvo la presupuesta afirmación, a menudo formulada irónicamente, de que no hay nada que afirmar). Un ejemplo central de esta actitud es la poesía de Philip Larkin (1922-85), uno de cuyos poemas se llama precisamente "Nothing to be Said", Nada que decir, y en donde se lee: ${ }^{9}$

Hours giving evidence

Or birth, advance

On death equally slowly

And saying so to some

Means nothing; others it leaves

\footnotetext{
3 "Cascando", parte 2 (ed. cit. , p. 30).

'Cit. por Alastair Fowler, $A$ History of English Literature (Cambridge:Harvard University

Press, 1991) ,pp. 368-69
} 
And saying so to some

Means nothing; others it leaves

Nothing to be said.

Horas dando evidencia

o nacimiento, avance

sobre la muerte igual de lento

y el decir esto a algunos

no significa nada; a otros deja

nada que decir. poemas.

Establecidas estas conexiones podemos tal vez volver a Beckett mismo en sus

\section{La enunciación}

1. Un ejemplo de nuestro primer concepto es "Da tagte es", ${ }^{10}$ de la serie "Echo's Bones", que transcribo primero en el original y luego en una traducción ajena "1 que he retocado levemente:

\section{Da Tagte Es}

redeem the surrogate goodbyes

the sheet astream in your hand

who have no more for the land

and the glass unmisted above your eyes

El título: del verbo alemán tagen, relacionado con Tag 'día', que en su forma impersonal significa algo así como 'quebrar albores, amanecer'. En mi traducción, que no pretende ser perfecta, he aquí lo que resulta:

\section{Da Tagte Es}

redime los adioses sucedáneos

la sábana que navega en tu mano ${ }^{12}$

\footnotetext{
${ }^{10}$ Ed. cit., p. 27. "Da tagte es", en alemán, aproximadamente 'allí (en ese punto del tiempo) amaneció'.

${ }^{11}$ Talens, en la ed. española citada, pp. 80-81.

12 Según el Webster's Third New International Dictionary (Springfield, Mass.: MerriamWebster, 1986), astream significa 'streaming'o, más en el contexto de este poema, in line with the stream'.
} 
los que nada más tienen para la tierra

y el cristal no empañado encima de tus ojos

He hablado de una enunciación peculiar, y creo que ella se advierte en este poema. Por decirlo de una manera poco técnica, es una poesía sin excusas. Está más allá de las costumbres de un lenguaje: simplemente enuncia, y puede llegarse a ella desde el inglés o el francés, desde el alemán o el español. No ofrece claves, al menos en su superficie, para la comprensión como proceso de búsqueda de equivalencias. Elimina toda redundancia y, como en una pieza de Schönberg o de Webern, nos ofrece su frase musical una única vez. Parece decirnos. yo digo (yo emito mi música) ,tú haz el esfuerzo de entender.

\section{Referencialidad}

2 Otros poemas de Beckett son aún más abstrusos; el que hemos visto, al menos, parece mantener una cierta continuidad en las imágenes, y no inserta referencias culturales que desconcierten al lector. En este último sentido, las menciones de lugares y los ecos de conocimientos y lecturas suelen entablar un contrapunto que puede obsesionar a algún lector de costumbres cómodas. La referencialidad erudita, en Beckett como en Pound y a veces en Eliot, puede ser abrumadora. ¿Qué haremos, por ejemplo, con Dortmunder", ${ }^{13}$ otro de los poemas del ciclo "Echo's Bones"?

Cuando leemos por primera vez este breve poema, encontramos que los términos o vocablos problemáticos son varios. Está la palabra del título, que en alemán designa al nativo de la ciudad de Dortmund, pero es también una marca de cerveza. Hay una referencia específica a K'in (que también se escribe $\mathrm{Ch}^{\prime} i n$ ), una de dos posibles dinastias chinas, la primera del siglo VI antes de Cristo y la otra (posiblemente la que se quiere mentar) del siglo XII de nuestra era. Llegamos de pronto al nombre propio Habbakuk, que pertenece más a nuestra cultura en la medida en que se refiere al libro de uno de los profetas menores del Antiguo Testamento (en español, Habacuc). La frase "the plagal east", el oriente plagal, no es inmediatamente interpretable. Al principio y al final del poema aparecen referencias a Homero y a Schopenhauer, que producen una relativa impresión de familiaridad en las cercanias de las anteriores. Hablo casi exclusivamente, en este caso, de los nombres propios; pero eso no indica que las frases que contienen sólo sustantivos comunes sean siempre más fáciles de descodificar.

¿Intentaremos una traducción de este poema? Leamos primero el original:

\footnotetext{
${ }^{13}$ Ed. cit. p. 16
} 


\section{Dortmunder}

In the magic the Homer dusk

past the red spire of the sanctuary

I null she royal hulk

hasten to the violet lamp to the thin K'in music

[of the bawd.

She stands before me in the bright stall

sustaining the jade splinters

the scarred signaculum of purity quiet

the eyes the eyes black till the plagal east

shall resolve the long night phrase.

Then, as a scroll; folded,

and the glory of her dissolution enlarged

in me, Habbakuk, mard of all sinners.

Schopenhauer is dead, the bawd

puts her lute away.

Con las reservas del caso, con plena conciencia de la imposibilidad de traducir en forma plena un poema como éste, he aquí mi versión:

\section{Dortmunder}

En la magia la penumbra de Homero más allá de la roja pirámide del santuario yo anodino ella el casco de un buque real marchando aprisa hacia la lámpara violeta al son de la delgada música K'in de la celestina.

Ella está de pie ante mí en el compartimento iluminado sosteniendo las astillas de jade el signaculum cubierto de cicatrices del puro silencio los ojos los ojos negros hasta que el oriente plagal resuelva la larga frase de la noche. Luego, como un pergamino, plegada, y la gloria de su disolución aumentada en mi, Habacuc, hez de los pecadores. Schopenhauer ha muerto, la celestina guarda su laúd.

Tal vez ahora, al hacer el esfuerzo de leer a Beckett en español, podamos percibir un poco mejor la estrategia discursiva de este poema. El título es equivoco, - casual, o una referencia privada a una botella de cerveza. A diferencia de lo que ocurre con otros títuios, que cumplen una función mínimamente orientadora o desambiguadora, en el caso de éste podemos prescindir de él sin que sufra nuestra lectura. En el poema mismo, el contexto que más nos ayuda es el que presenta a 
nuestra imaginación la escena de un encuentro sexual en el Oriète, rodeado de una atmósfera ceremonial y de un goce que no es el de un solo sentido. La música aparece tres veces: dos como marco o trasfondo del encuentro -el tipo de música de la dinastía K'in y el laúd de la cortesana- y una en esa bella pero imprevista imagen, la de la noche como una larga frase de canto gregoriano, que no terminará mientras el alba no introduzca una cadencia plagal (los modos plagales son caracteristicos de la música litúrgica, y una cadencia plagal -es decir, formada sobre los grados I-IV de la escala- es la que corresponde a la palabra "Amén" en los himnos protestantes). Dentro de la casa, más allá de la roja pirámide situada en el mundo exterior, el color del jade representa lo intimo y también lo bello, en contrapunto con los negros ojos de la mujer. El goce no es sin culpa: Habacuc dirige una terrible imprecación hacia sí mismo. Pero la misoginia de Schopenhauer no tiene la última palabra: al menos es posible el encuentro de los cuerpos en la noche oriental. En 14 líneas, como se ve, hay un cúmulo de referencias eruditas: esta escritura para lectores privilegiados puede verse -a partir de Joyce, Eliot y Pound, por lo menos como una de las marcas distintivas de la modernidad.

\section{Repetición}

3. En tercer lugar el elemento de repetición está siempre presente. ¿Por qué la repetición? Posiblemente debido a la insuficiencia de la palabra; porque ésta no es del todo significativa, como creyeron los románticos y los simbolistas. La repetición llena un vacio que no sólo es carencia de vibraciones, sino también insuficiencia de sentido. Apela, en cierta forma, a la función fática del lenguaje; la reiteración de una palabra o expresión no la toma necesariamente más transparente, pero al menos procura mantener la comunicación. Hay ejemplos por doquier(y, desde luego, no sólo en la poesía, sino aun más en el diálogo teatral y en la narrativa beckettianas); de hecho, hay una suerte de dicción absurdista básica, en la cual la repetición del fragmento adquiere características predominantes.

Tomemos sobre esto "Enueg \|\|$^{14} 14$ y hagamos un rápido repaso. En la línea 1 , "world world world world" (mundo mundo mundo mundo). Línea 2, "and the face grave" (y el rostro serio), seguido en la línea 5 por "and the face crumbling shyly" (y el rostro desmoronándose tímidamente). Líneas 9 y 10, "veronica mundi / veronica munda": repetición con juego de palabras. Líneas 15 y 17 , respectivamente "feet in marmalade" y "heart in marmalade" (los pies en mermelada, el corazón en mermelada) Línea 19, the heart do the old heart" (el viejo corazón el viejo corazón). Líneas 6 y 18, casi idénticas pero contrapuestas, respectivamente "too late to darken the sky" (demasiado tarde para ensombrecer el cielo ) y "too late to brighten the sky" (demasiado tarde para iluminar el cielo). Línea 21, "doch I assure thee" (doch [es decir, no obstante' en alemán] te aseguro) y línea 29, "doch doch I assure thee" (doch doch te aseguro). Dejo de lado los muchísimos casos (algunos no del todo

${ }^{14}$ Ed.;cit.,pp. 13-14. 
distinguibles de los anteriores) en que la repetición toma la forma de lo que la retórica llama "anáfora", un recurso que subraya el paralelismo de determinadas construcciones; asi, en el mismo texto, líneas 25-26, "shining round the corner like an anthrax / shining on Guinness's barges" (brillando a la vuelta de la esquina como un carbunclo / brillando sobre las barcazas de Guinness".

Para que se vea que la predilección por la repetición no caracteriza sólo a un tipo de poemas, pasamos a los textos en francés de Mirlitonnades y encontramos, entre otros, los dos siguientes: ${ }^{15}$

imagine si ceci
un jour ceci
un beau jour
imagine
si un jour
un beau jour ceci
cessait
imagine
$Y$ este otro: ${ }^{16}$
écoute-les
s'ajouter
les mots
aux mots
sans mot
les pas
aux pas
un à
un

Leamos ahora los mismos poemas en español ,en la traducción de Lucas Margarit incluida en el número 3 de Beckettiana. ${ }^{77}$ En el mismo orden:

imagina si esto.

un día esto

un buen día imagina

\footnotetext{
${ }^{15}$ Ed. cit., p. 73

${ }^{16}$ Ed. cit., p. 71

${ }^{17}$ p. 38.
} 


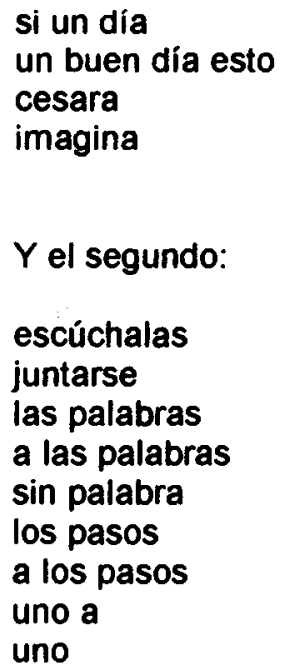

Prodigios de la repetición: cada vez que reaparece una palabra, su valor cambia, cambia su matiz, aunque sea en pequeñisima medida. Como ocurre con las frases de una composición musical, en el poema la palabra repetida no es nunca igual a la palabra en soledad y ello es explicable, porque toda vez que una palabra reaparece, su contexto ha variado. Y la palabra no significa sola, sino en función de su contexto.

\section{Deixis}

4. Muy rápidamente, quisiera decir que to que podria llamarse "falsa deixis", y también "deixis vacía" (gestos deicticos sin resolución), asi como las referencias que han sido elididas en el proceso compositivo, son también escollos -o desafios- para la comprensión de esta poesía. En lo que llevamos leído han aparecido suficientes ejemplos; agreguemos dos más.

El primero es el comienzo de uno de los "Seven Poems", el titulado "Cascando"18" why not merely the despaired of / occasion of/, wordshed // is it not better abort than be barren" (por qué no simplemente el desesperado de / ocasión de / vertedero de palabras // no es mejor abortar que ser estéril". Como se ve, la fragmentación contribuye a una suerte de alejamiento entre la palabra y el sentido, una carrera de obstáculos para el lector, que debe seguir leyendo para llegar a algún tipo de tierra firme.

\footnotetext{
${ }^{18}$ Ed. cit., p. 29
} 
El otro ejemplo viene de los "Poèmes 1937-1939", en francés, se titula "Dieppe" y comienza asi: "encore le dernier reflux / le galet mort / le demi-tour puis les pas / vers les vieilles lumières" (de nuevo el último reflujo / el guijarro muerto / el volver luego los pasos / hacia las luces antiguas).

Desde luego, siempre será posible "entender" de alguna manera estos versos: como dice Octavio Paz, la poesía es inexplicable, pero no ininteligible. Sin embargo, como en los casos anteriores, el extremo despojamiento verbal puede llegar a ser percibido por el lector como una ausencia, una zona de sombra que se interpone entre el texto escrito y él mismo. Sólo se puede sospechar en Beckett una actitud deliberada: no hay alli descuido alguno, sino la prosecución implacable de una poética.

\section{Ausencia y silencio}

5. Una poética, dije. Una poética que no está manifestada a través de preceptos sino en la práctica misma de la poesía, y que a veces se filtra entre los versos.

Es una poética de la ausencia y el silencio. Se canta la ausencia, lo que no está y, con la voz que no se tiene, se canta la ausencia de una voz.

El mundo, por contradictoria que sea esta expresión, es un lugar de ausencia. Dice así uno de los poemas en francés, que transcribiré intercalando una traducción al español: ${ }^{19}$

que ferais-je sans ce monde sans visage sans questions

où être ne dure qu'un instant où chaque instant

verse dans le vide dans l'oubli d'avoir été

sans cette onde où à la fin

corps et ombre ensemble s'engloutissent

(qué haré sin este mundo sin rostro sin preguntas

donde ser no dura más que un instante donde cada instante

derrama en el vació en la ignorancia de haber sido

sin esta onda donde al final

se sumergen juntos el cuerpo y la sombra)

que ferais-je sans ce silence gouffre des murmures

haletant firieux vers le secours vers l'amour

sans ce ciel qui s'éléve

sur la poussière de ses lests

(qué haré sin este silencio abismo de murmullos

jadeando furioso hacia el socorro hacia el amor

sin este cielo que se eleva

por sobre el polvo de sus lastres)

${ }^{19}$ Ed. cit., p. 60; trad. inglesa de Beckett, p. 61. 
Fugacidad y ausencia son las marcas de este mundo que la poesia, a su vez, sólo puede reflejar con la atroz soledad de las palabras ("dans un espace pantin I sans voix parmi les voix / enfermées avec moi": en un espacio títere / sin voz entre las voces / encerradas conmigo; y también en "Enueg I"20: "Ah the banner / the banner of meat bleeding / on the silk of the seas and the arctic flowers / that do not exist": ah la enseña / la enseña de carne sangrante / sobre la seda de los mares y las flores árticas / que no existen).

$Y$ sin embargo, es preciso actuar; ya que, como se dice en "Cascando", ${ }^{21}$ resemantizando un apotegma bien conocido, "all always is it better too soon than never", todo siempre es mejor pronto que nunca. A pesar de todo, el hombre lucha contra la nada que lo circunda, y que quizá esté ante todo dentro de sí; y la poesía, para citar una línea de "Alba", podría equipararse a "a statement of itself drawn across the tempest of emblems", una declaración de si misma arrastrada a través de la tempestad de los emblemas. $Y$ un ejemplo más, quizá el último, de los poemas en francés: ${ }^{22}$

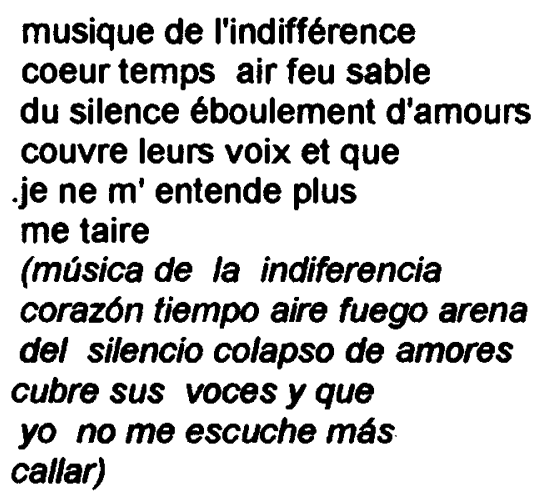

La valoración del silencio como elemento fundante de la poesía y quizá de toda literatura, me parece el aspecto más característico de toda esta producción poética de Samuel Beckett. Los demás rasgos que he ido señalando -la enunciación desde el plurilingüismo, la referencialidad erudita, la repetición como clave lingüística, el tipo especial de deixis y referencias elididas- pueden verse como características generales del proceso poético de la vanguardia. Frente a todo ello, hay por lo menos un rasgo más que no es otra cosa que el trasvasamiento poético del total de la personalidad literaria de Beckett: la búsqueda y puesta en práctica de una estética del silencio.

Al decir que vanguardia y silencio definen esta poesía, no ignoro que ambos conceptos son equívocos, o por lo menos resbalosos. Se podría objetar que la idea de "vanguardia" se resiste un poco a integrarse con ese permanente

${ }^{20}$ Ed. cit. , p. 12
${ }^{21}$ Ed. cit. , p. 29
${ }^{22}$ Ed. cit. , p. 46 
idea de "vanguardia" se resiste un poco a integrarse con ese permanente desenterrar de referencias que vienen de muy atrás, de los siglos clásicos, de la práctica poética de los trovadores, de los mundos germánico y románico, ${ }^{23}$ ' de toda una cultura que se va destilando en las líneas del poema. Y se podría decir también que. poesía y silencio son términos mutuamente excluyentes, contradictorios, ya que no hay forma de hacer poesía que no sea con palabras, y las palabras parecen ser -al menos, en la experiencia cotidiana- lo contrario del silencio.

Pero ambas objeciones son falaces. En cuanto a la primera baste decir que el uso moderno y posmoderno de los elementos de la cultura difiere fundamentalmente del que ellos recibian en siglos anteriores: el uso que se les da ahora no es el del "scholar", sino el del "bricoleur" $Y$ en cuanto a lo segundo: Beckett, entre otros, sabe que no hay más remedio que usar palabras, pero eso no le impide usarlas de tal manera que entre los intersticios que van dejando .en su incompletud, su despojamiento, en su deliberada pobreza. se filtre el silencio que nos rodea, que es a la vez el silencio de un cosmos incomprensible y el nuestro propio en la incapacidad de alcanzar nuestra expresión.

\section{Visión de conjunto}

Un conspicuo observador de la escena literaria contemporánea, el británico Martin Seymour-Smith, escribe (mi traducción): ${ }^{24}$

Beckett es heladamente cómico, pero es como si siempre hubiera mirado a Chaplin, uno de sus inspiradores, a la luz de la tragedia y la preocupación. $\mathrm{Ha}$ purgado su literatura de la riqueza y el humor que indudablemente él posee, porque desea demostrar que la literatura -un cuento narrado en la oscuridad para espantar la ausencia de significado de la vida y lo inevitable de la decadencia- no tiene sentido alguno. En cuanto a esto es un irónico comediante, y el hombre mismo está tan conspicua pero desvergonzadamente ausente de su propia obra como puede estarlo cualquier escritor moderno. [...] Soberbio como laureado del absurdo, Beckett no ofrece misterio alguno en su obra, sólo desesperación: la apoteosis de la alittérature, ese fenómeno francés absolutamente contemporáneo; y sin embargo, es un hombre que pertenece al pasado, un devoto seguidor de los pensadores del pasado: necesita una

\footnotetext{
${ }^{23}$ Aun cuando esas menciones aparezacan borrosas, y a veces deliberadamente incorrectas, en una actitud de desprecio por lo que Pound, con irónica ortografia, llamaba "Kulchur". Así ocurre cerca del comienzo de "Whoroscope"(ed. cit., p. 1) : "Galileo how are you / and his consecutive thirds". A propósito -así lo delata el cambio de persona verbal- se confunde a Galileo Galilei con su padre, Vincenzo Galilei, el teórico musical autor del Dialogo della musica antica e della moderna ( Florencia, 1581; hay una edición moderna al cuidado de Fabio Fano [Milano: Alessandro Minuziano, 1947] ).

${ }_{24}^{4}$ Martin Seymour-Smith, Who's Who in Twentieth Century Literature (New York: Rinehart and Winston, 1976), p. 48.
} 
certidumbre, y si no puede encontrarla en algo la encontrará en la nada, que disecciona con medieval minuciosidad y, más recientemente, con monotonía.

Esa es también la imagen de Beckett que surge de su poesía, a la que por cierto no consideramos una parte intrascendente de su obra, sino una síntesis de la obra misma, un punto focal. En ese manojo de poemas se concentran los rayos de una luz negra que nos deslumbra en la eficacia de su inexistencia: una luz paradojica que, sin embargo, ilumina nuestra condición y nos hace reflexionar sobre el lugar que los hombres, y nuestras desesperadas tentativas de construir algo en el vacio, ocupamos en el universo. 